\title{
DO (DES)CABIMENTO DO IRDR EM AÇÕES DE COMPETÊNCIA ORIGINÁRIAS E RECURSAIS ORDINÁRIAS NO STF E NO STJ ${ }^{1}$
}

THE (UN)APPROPRIATENESS OF IRDR IN ORIGINAL JURISDICTION ACTIONS AND ORDINARY APPEALS IN THE STF AND STJ

Júlio César Rossi Pós-Doutor pela Universidade de Coimbra (UC/PT). Estágio pós-doutoral na Universidade do Vale do Rio dos Sinos (UNISINOS). Doutor pela Pontifícia Universidade Católica de São Paulo (PUC/SP). Mestre pela Universidade Estadual Paulista "Júlio de Mesquita Filho" (UNESP). Membro da Associação Brasileira de Direito Processual (ABDPro). Advogado da União (AGU). Brasília/DF. E-mail: julio_rossi@uol.com.br.

Luís Gustavo Reis Mundim Mestre e especialista em Direito Processual pela Pontifícia Universidade Católica de Minas Gerais (PUC/MINAS). Pósgraduando em Gestão de Negócios pela Fundação Dom Cabral. Membro da Associação Brasileira de Direito Processual (ABDPro), Academia de Direito Processual (ACADEPRO) e Instituto Popperiano de Estudos Jurídicos (INPEJ). Advogado e professor universitário. Belo Horizonte. E-mail: luis.mundim@ reismundim.adv.br.

RESUMO: O trabalho procura, a partir de uma análise crítica, estabelecer a natureza jurídica sui generis do IRDR e o seu cabimento perante os Tribunais de Justiça dos Estados e Tribunais Regionais Federais, demonstrando sua vocação perante essas Cortes no enfrentamento da litigiosidade serial. Dessa constatação serão traçadas as principais razões

\footnotetext{
${ }^{1}$ Artigo recebido em 17/10/2021 e aprovado em 22/11/2021.
} 
pelas quais o IRDR não deve ser admitido em ações de competência originária e tampouco em recursos de aptidão ordinária processados perante o STF e do STJ.

PALAVRAS-CHAVE: IRDR; competência; ações originárias; Supremo Tribunal Federal; Superior Tribunal de Justiça.

ABSTRACT: The paper seeks, from a critical analysis, establish the sui generis legal nature of the IRDR and its suitability before the State Courts of Justice and Federal Regional Courts, demonstrating its vocation before these Courts in facing the serial litigiousness. From this observation will be outlined the main reasons why the IRDR should not be admitted in actions of original jurisdiction and neither in resources of ordinary suitability processed before the STF and STJ.

KEYWORDS: IRDR; jurisdiction; original lawsuits; Federal Supreme Court; Superior Court of Justice.

A única coisa que nos permite concordar com uma teoria errônea é a falta de uma melhor.

John Rawls.

\section{INTRODUÇÃO}

O trabalho tem por objetivo estabelecer a natureza jurídica do Incidente de Demandas Repetitivas - IRDR, disciplinado nos arts. 976 usque 987 do CPC, concluindo, tratar-se de instituto genuinamente brasileiro.

A partir do que se cognomina "vocação" do IRDR será demonstrada sua hipótese de cabimento perante os Tribunais que compõem a justiça comum, quais sejam: os Tribunais de Justiça e Tribunais Regionais Federais.

Justifica-se, à guisa conclusiva, as razões pelas quais o instituto processual não deve ser admitido perante o STF e o STJ, particularmente, em relação às ações originárias e recursal-revisional ordinárias processadas nesses Tribunais, pois, faltam-lhes competência funcional para conhecer, processar e julgar o "incidente". 


\section{NATUREZA JURÍDICA DO IRDR: DA MERA INSPIRAÇÃO À CONCRETIZAÇÃO DE UM INSTITUTO MADE IN BRAZIL}

A doutrina que se dedicou ao estudo sobre o tema não fornece um entendimento uníssono acerca da natureza jurídica do IRDR.

Em regra, os juristas partem da distinção entre "causa piloto" ou "procedimentomodelo". O primeiro, grosso modo, seria definido como sendo uma espécie de "processoteste", no bojo do qual julga-se o caso concreto e estabelece-se uma tese a ser aplicada às demais hipóteses, ou seja, mesma matéria. O último, caracteriza-se em um incidente pelo qual há uma espécie de cisão procedimental em fases cognitiva e decisória. Determina-se, portanto, um incidente procedimental que, uma vez julgado o caso, fixando-se uma determinada tese jurídica, esta poderá ser replicada em todos os eventuais processos cujo objeto seja a mesma matéria (causas repetitivas).

Confessadamente, o IRDR surge da inspiração no procedimento-modelo alemão (Musterverfahren), mas sua concretização no CPC em vigor, traz características típicas da hipótese de "causa piloto", na medida em que há uma única decisão em relação ao mérito da demanda (tese) que deverá ser aplicada aos casos análogos. Julga-se a "questão" de direito comum, bem assim as peculiaridades do caso individual apresentado. No genuíno procedimento-modelo, como, por exemplo, o alemão e o português (ambos já revogados, porque foram, de certo modo, regimes temporários e com finalidades específicas), o tribunal decide fixando uma tese quanto à "questão" objeto do procedimento, a ser aplicada aos casos assemelhados, devolvendo-se ao órgão julgador originário, as demais matérias para que profira o julgamento da causa. Há, portanto, uma efetiva cisão de fases (cognitiva e decisória).

Nota-se, portanto, que embora existam grandes diferenças entre os chamados "casos-pilotos" e os "procedimentos modelos", fato é que nosso IRDR não se identifica puramente nem com um, nem com o outro.

Na realidade, o nomem iuris do instituto é uma sequência de equívocos e não condiz com sua procedimentalidade. 
Em primeiro lugar não há solução de "demanda" - manifestação do direito de ação ou pretensão deduzida pelo autor/recorrente -, mas de "questões"2 da demanda ponto(s) controvertido(s) de fato/direito ${ }^{3}$ material ou processual sobre o(s) qual(is) exige(m)se prévia solução, dada(s) a(s) sua(s) influência(s) ou consequência(s) à resolução do meritum causae.

Há robusto entendimento no sentido de faltar ao IRDR a natureza de incidente procedimental, pois é despido de todas as características essenciais próprias dessa espécie, a saber: acessoriedade, incidentalidade e acidentalidade.

Partindo-se da premissa de que o incidente é uma questão, um aspecto, um ponto a ser analisado no bojo de uma ação ou recurso (=processo preexistente), instaurando-se, desse modo, um procedimento paralelo e autônomo ao processo principal ${ }^{4}$, Marcos Cavalcanti $^{5}$ e Ricardo Yamin Fernandes ${ }^{6}$, em síntese, afastam cada uma dessas características ínsitas aos autênticos incidentes procedimentais.

Não há instauração de procedimento com o fito de solucionar questão incidental. A dicção do art. 978, parágrafo único estabelece, que "o órgão colegiado incumbido de julgar o incidente e de fixar a tese jurídica julgará igualmente o recurso, a remessa necessária ou o processo de competência originária”.

No IRDR não se resolverá questão incidental (prévia/prejudicial de mérito), mas o mérito recursal, provendo-se ou desprovendo-se a pretensão levada no bojo do meio de impugnação, na remessa necessária ou no processo de competência originária. Não se cria

\footnotetext{
${ }^{2}$ Nesse sentido, destacamos: CAVALCANTI, Marcos de Araújo. Incidente de resolução de demandas repetitivas (IRDR) [livro eletrônico]. São Paulo: RT, 2016; ROSSI, Júlio César. Crítica ao incidente de resolução de demandas repetitivas: das inadequações às inconstitucionalidades. Curitiba: Juruá, 2016. Versão digital. MEDINA, José Miguel Garcia. Curso de direito processual civil moderno [livro eletrônico]. 4. Ed. São Paulo: RT, 2018 e ROCHA, Alexandre. Julgamento de casos repetitivos e processo constitucional. Belo Horizonte: D'Plácido, 2018, p. 69.

${ }^{3} \mathrm{O}$ art. 976 que estabelece os requisitos para a instauração do IRDR comete uma impropriedade ao dispor, em seu inciso I, que a controvérsia serial deve ser "a mesma questão unicamente de direito". Não há cisão entre questões de fato e de direito. Toda questão é "jurídica", compreendendo necessariamente, fato e direito que se entrelaçam em um todo. Há "solidária influência entre fato e direito. "Puro fato" e o "puro direito" não se encontram nunca na vida jurídica. Portanto, é inimaginável a pretendida dissensão. Nesse sentido: NEVES, Antônio Castanheira. Questão-de-facto e questão-de-direito. O problema metodológico da juridicidade (ensaio de uma reposição crítica). Coimbra: Almedina, 1967.p. 586-587.

${ }^{4}$ ABELHA, Marcelo. Suspensão da segurança: sustação da eficácia de decisão proferida contra o Poder Público. 2. ed. São Paulo: RT, 2006, p. 39.

5 CAVALCANTI, Marcos de Araújo. Incidente de resolução de demandas repetitivas (IRDR) [livro eletrônico]. São Paulo: RT, 2016.

${ }^{6}$ FERNANDES, Ricardo Yamin. Do incidente de assunção de competência [livro eletrônico]. São Paulo: Thomson Reuters Brasil, 2020.
} 
um incidente, uma nova relação jurídica ou novo meio de impugnação. Há, por imposição legal (CPC, art. 978) e nos termos dos regimentos internos dos Tribunais de Justiça e dos Tribunais Regionais Federais uma espécie de transmissão/cedência da competência do julgamento do IRDR para um órgão interno hierarquicamente superior, nos termos da norma regimental de cada um dos respectivos Tribunais locais/regionais.

Com efeito, o IRDR não se caracteriza como sendo puramente (i) "causa-piloto"; (ii) "procedimento-modelo" ou (iii) incidente procedimental, sobrando-lhe a alcunha de "técnica" procedimental, que, data maxima venia, nada esclarece acerca da natureza jurídica da categoria procedimental referida, salvo a insofismável conclusão de que se trata de algo dissonante dos institutos conhecidos, restando-nos, o adjetivo "brasileiríssimo"7.

Se o IRDR vai cumprir as promessas ousadas defendidas por seus idealizadores e admiradores, somente o tempo e a experiência vão nos revelar; por ora, nos resta analisálo e descrevê-lo e, naquilo que importa, reconhecer que se está diante de um instituto made in brazil, disponível para aqueles que pretendam exportá-lo para algum país que possa se interessar em "comprar" essa ideia.

\section{A VOCAÇÃO DO INSTITUTO: AS HIPÓTESES DE CABIMENTO PERANTE OS TRIBUNAIS DE JUSTIÇA E TRIBUNAIS REGIONAIS FEDERAIS E AS RAZÕES PELAS QUAIS O IRDR NÃO DEVE SER ADMITIDO EM AÇÕES DE COMPETÊNCIA ORIGINÁRIA E RECURSOS DE APTIDÃO ORDINÁRIA DO STF E DO STJ}

Parece-nos que o IRDR, ao compor um plexo de procedimentos tendentes a solucionar a litigiosidade repetitiva - causas e/ou recursos cujas questões possam ser consideradas "conflitos de massa", por deterem aspectos "comuns" - é direcionado, no que se pode chamar justiça comum aos Tribunais de Justiça e aos Tribunais Regionais Federais, uma vez que no âmbito dos Tribunais Superiores (STF e STJ), o CPC estabeleceu os recursos excepcionais repetitivos (RE e REsp), criando, inclusive uma vedação expressa no art. 976, $\S 4 .^{\circ}, \mathrm{CPC}$ : "É incabível o incidente de resolução de demandas repetitivas quando um dos

\footnotetext{
${ }^{7}$ NEVES, Daniel Amorim Assumpção. Manual de direito processual civil. 12. Ed. Salvador: Juspodivm, 2020, 1.513 .
} 
tribunais superiores, no âmbito de sua respectiva competência, já tiver afetado recurso para definição de tese sobre questão de direito material ou processual repetitiva".

Ao menos no âmbito recursal, a doutrina não diverge dessa interpretação do dispositivo legal, sustentando que o "IRDR somente pode ser suscitado perante Tribunal de

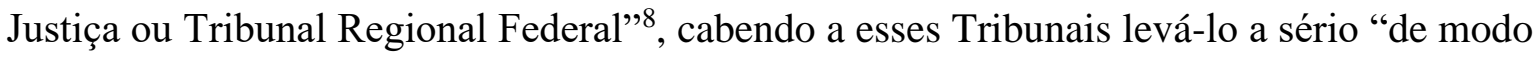
que a nova técnica auxilie na melhoria quantitativa e, especialmente, qualitativa de seus julgamentos" $"$.

Note-se que o art. 977 do CPC “deixa claro que a competência para julgar a questão prejudicial posta no incidente é do Tribunal de Justiça, Regional Federal ou Regional do Trabalho -, seja quando as demandas repetitivas que dão origem ao delineamento da questão estão em primeiro grau de jurisdição, seja quando já estão no tribunal, em vista da interposição de recursos de apelação" ${ }^{10}$, sendo, portanto, o juízo de admissibilidade do IRDR aferido no "tribunal de segundo grau", como sustentam, por exemplo: Rossi ${ }^{11}$, Medina ${ }^{12}$, Nery-Nery ${ }^{13}$, Assis ${ }^{14}$, Monnerat ${ }^{15}$, Volpe ${ }^{16}$, Wambier e Talamini ${ }^{17}$, Bueno ${ }^{18}$, Ribeiro ${ }^{19}$ e Rocha $^{20}$.

\footnotetext{
${ }^{8}$ CAVALCANTI, Marcos de Araújo. Op. cit.

9 NUNES, Dierle. O IRDR do Novo CPC: este "estranho" que merece ser compreendido. Revista Justificando: http://justificando.com/2015/02/18/o-irdr-novo-cpc-este-estranho-que-merece-ser-compreendido. Acesso: 08/10/2021.

${ }^{10}$ MARINONI, Luiz Guilherme. Incidente de resolução de demandas repetitivas [livro eletrônico]: decisão de questão idêntica x precedente. 2. Ed. São Paulo: Thomson Reuters Brasil, 2019.

${ }^{11}$ ROSSI, Júlio César. Crítica ao incidente de resolução de demandas repetitivas: das inadequações às inconstitucionalidades. Curitiba: Juruá, 2016. Versão digital.

${ }^{12}$ MEDINA, José Miguel Garcia. Curso de direito processual civil moderno [livro eletrônico]. 4. Ed. São Paulo: RT, 2018.

${ }^{13}$ NERY JUNIOR, Nelson; NERY, Rosa Maria de Andrade. Código de processo civil comentado [livro eletrônico]. 5. Ed. São Paulo: Thomson Reuters Brasil, 2020.

${ }^{14}$ ASSIS, Araken. Manual dos recursos [livro eletrônico]. 4. Ed. São Paulo: Thomson Reuters, 2021.

${ }^{15}$ MONNERAT, Fábio Victor da Fonte. Súmulas e precedentes qualificados. São Paulo: Saraiva, 2019, p. 331.

${ }^{16}$ VOLPE CAMARGO, Luiz Henrique. A centralização de processo como etapa necessária do incidente de resolução de demandas repetitivas. 2017. Tese (Doutorado em Direito) - Faculdade de Direito, Pontifícia Universidade Católica de São Paulo (PUC-SP), 2017, p. 123-124.

17 WAMBIER, Luiz Rodrigues; TALAMINI, Eduardo. Curso avançado de processo civil: cognição jurisdicional (processo comum de conhecimento e tutela provisória) - vol. 2, 16. ed. São Paulo: RT, 2016, p. 728.

${ }^{18}$ BUENO, Cassio Scarpinella. Manual de Direito Processual Civil. 2. Ed, São Paulo: Saraiva, 2016, p. 283, 651-652.

${ }^{19}$ RIBEIRO, Sérgio Luiz Almeida. Incidente de Resolução de Demandas Repetitivas - IRDR: o procedimento padrão tupiniquim e suas peculiaridades; Revista Brasileira de Direito Processual - RBDPro, n. 92. Belo Horizonte, out/dez. 2015, p. 190.

${ }^{20}$ ROCHA, Alexandre. Julgamento de casos repetitivos e processo constitucional. Belo Horizonte: D'Plácido, 2018, p. 71.
} 
Uma vez admitido o "incidente", dispõe o art. 982, I, do CPC que "o relator suspenderá os processos pendentes, individuais ou coletivos, que tramitam no Estado ou na região, conforme o caso", não havendo dúvidas quanto a instância vocacionada para o conhecimento, processamento e julgamento do IRDR.

A polêmica surge em relação à possibilidade de instauração do "incidente" em ações de competência originária e recursos de processamento ordinário perante o STF e do STJ.

Parcela da doutrina sempre sustentou a possibilidade do cabimento do IRDR nos tribunais superiores em relação às "demandas de competência originária e em outros tipos de recursos no âmbito dos tribunais superiores", não havendo "absolutamente nada, no teto normativo que impeça". Articulam que o art. 978 do CPC, "atende ao que determina o art. 96 da Constituição Federal", cabendo aos "tribunais elaborar seus regimentos internos, dispondo sobre a competência e o funcionamento dos respetivos órgãos jurisdicionais e administrativos. Cabe aos tribunais fixar seus órgãos e suas respectivas competências internas, não devendo o legislador imiscuir-se nesse assunto"21.

Na mesma perspectiva, defende, Aluisio Gonçalves de Castro Mendes, que a matéria objeto do IRDR poderá chegar ao conhecimento dos Tribunais Superiores por meio da interposição de recursos repetitivos, tratando-se de competência recursal daquelas Cortes, além da possibilidade de sua instauração nas causas originárias ${ }^{22}$.

Sob ponto de vista semelhante, Vinícius Silva Lemos propugna que o IRDR "funcionaria como um preenchimento das lacunas que os recursos excepcionais repetitivos não influenciam, possibilitando, portanto, que todas as cognições em grau superiores possam ser julgadas em ritos repetitivos, contudo separados pelos institutos atinentes a cada processo. Nos recursos excepcionais, o sistema próprio de repetitividade e nos demais o IRDR" ${ }^{23}$.

Não faltam vozes, por exemplo, perfilhando que "da mesma forma em que não se restringiu na lei processual o cabimento do IRDR apenas nos processos de competência

${ }^{21}$ DIDIER JR, Fredie; CUNHA, Leonardo Carneiro da. Curso de direito processual civil. vol. 3. 17. Ed. Salvador: Juspodivm, 2020, p. 781-782.

${ }^{22}$ MENDES, Aluisio Gonçalves de Castro. Incidente de resolução de demandas repetitivas: sistematização, análise e interpretação do novo instituto processual. Rio de Janeiro: Forense, 2017, p. 140-141.

${ }^{23}$ LEMOS, Vinícius Silva. Recursos e processos nos tribunais. 5. Ed. Salvador: Juspodivm, 2021. p. 1.0621.063 . 
originária dos tribunais estaduais e regionais, não há necessidade de adoção de interpretação neste ponto restritiva ao cabimento do IRDR no Superior Tribunal de Justiça apenas nos casos de competência originária" 24 .

Em meados de 2019, o STJ, no julgamento da Pet. n. ${ }^{\text {o } 11.838-M S, ~ e s t a b e l e c e u ~}$ que a "instauração de incidente de resolução de demandas repetitivas diretamente no Superior Tribunal de Justiça é cabível apenas nos casos de competência recursal ordinária e de competência originária e desde que preenchidos os requisitos do art. 976 do CPC"25.

$\mathrm{O}$ voto vencido, proferido pela Min. Laurita Vaz, no bojo do qual não se conhecia do "incidente", estabelecendo que a competência funcional do STJ em relação ao IRDR limitar-se-ia ao o exame de recurso especial manejado contra acórdão proferido por Tribunais Estaduais ou Tribunais Regional Federal e à análise de pedidos de suspensões, em todo território nacional, de causas que versam sobre idêntica controvérsia jurídica repetitiva.

O voto condutor do Min. João Otávio de Noronha acabou prevalecendo. Entre as razões de decidir destacam-se as seguintes:

(i) o IRDR - "é mais um mecanismo de coletivização de julgamentos voltado à gestão de demandas repetitivas, a fim de assegurar tratamento isonômico aos jurisdicionados e garantir maior segurança jurídica, previsibilidade e economia processual" - difere de outras modalidades processuais (recursais) afetáveis pelo rito dos repetitivos. Aliás, esse entendimento foi tomado pela Primeira Seção do STJ que, de ofício, desafetou o Conflito de Competência n. ${ }^{\circ}$ 148.519/MT (27.10.2017), por entender descabida a afetação de outras modalidades processuais que não o recurso especial, os embargos de divergência e o agravo em recurso especial para julgamento pelo rito dos recursos repetitivos;

(ii) o IRDR "possui natureza de incidente processual, como seu próprio nome revela", não se cuidando de "ação originária, até porque não pode o legislador comum criar competências originárias para os tribunais, as quais estão previstas na Constituição Federal no caso dos tribunais superiores". Para a instauração do novo instituto exige-se "a existência de demanda em curso no tribunal para que nela possa incidir";

\footnotetext{
${ }^{24}$ SOARES, Fábio Costa. Cabimento do incidente de resolução de demandas repetitivas. In: MENDES, Aluisio Gonçalves de Castro; PORTO, José Roberto Mello. Coords. Incidente de resolução de demanda repetitivas: panorama e perspectivas. Salvador: Juspodivm, 2020, p. 485.

${ }^{25}$ STJ, Corte Especial, AgInt-Pet 11.838-MS, Rel. orig. Min. Laurita Vaz [vencida], rel. p/ac. Min. João Otávio de Noronha, j. 7.8.2019, m.v., DJUe 10.9.2019.
} 
Dessa intelecção, comungada pela maioria dos Ministros da Corte, firmou-se o seguinte: é cabível o IRDR em ação de competência originária e recursal (revisão ordinária) no âmbito do STJ, desde que: $(\alpha)$ preenchidos os requisitos do art. 976 do CPC e $(\beta)$ demanda ou recurso tenham ultrapassados o juízo de admissibilidade e estejam pendentes de julgamento.

Salvo engano, após esse julgamento, o tema arrefeceu no âmbito doutrinário, tornando-se comum a sua menção para legitimar a admissão do IRDR perante os Tribunais Superiores.

Entretanto, ainda, revela-se imprescindível o enfrentamento do tema sob outras nuances. É o que se propõe a seguir enfrentar.

De plano, como salientado, o IRDR não se caracteriza como “incidente", motivo pelo qual se discorda da justificativa de "natureza de incidente processual, definida "pelo seu próprio nome" pelo STJ, no julgamento da AgInt-Pet 11.838-MS.

Não sendo, destarte, "incidente", qualquer outra espécie de ação ou recurso de competência originária do STJ deve ter assento constitucional, como, a propósito, restou claro no voto condutor da lavra do Min. João Otávio de Noronha.

Definindo-se a competência como sendo a aptidão para exercer um poder numa situação definida em lei (lato sensu) a partir de suas características próprias (natureza, matéria, localização etc.), verifica-se a viabilidade em defini-la deslocada dos critérios estabelecidos pelo órgão legislador encarregado de estabelecê-la ${ }^{26}$.

No caso dos arts. 102 e 105, incisos I e III, a competência funcional do STF e do STJ se revela como sendo da espécie "numerus clausus", cuja alteração, supressão ou ampliação deve ser efetivada através do procedimento específico das emendas à Constituição Federal (art. 60).

Nos supracitados dispositivos não há que se sustentar o exercício de "competências implícitas complementares", até porque não há "lacunas constitucionais evidentes", no arquétipo de uma Constituição analítica. Competência para processar determinadas classes de ações e/ou recursos nominados ad nauseam não permitem outra

\footnotetext{
${ }^{26}$ THÉRY, Philippe. Competência. In: ALLAND, Denis; RIALS, Stéphane (Orgs.). Dicionário de Cultura
} jurídica. São Paulo: WMF Martins Fontes, 2012, p. 280. 
forma de interpretação diversa daquela de cariz restritivo, como sustentam, doutrinariamente, Gilmar Mendes e Paulo Gustavo Gonet Branco $^{27}$ e Canotilho ${ }^{28}$.

Não por outro motivo, essa compreensão foi verberada pelo STF em mais de uma oportunidade entre 1993 e 2021, seja no controle difuso, seja no concentrado, por exemplo: ACO 359 QO/SP, Rel. Min. Celso de Mello, Tribunal Pleno, DJe 11.3.1994; Pet 1.738 AgR, Rel. Min. Celso de Mello, DJ 1.10.1999, AC 2.596 AgR, Rel. Min. Celso de Mello, Tribunal Pleno, DJe 15.04.2013, HC 119.884 AgR, Rel. Min. Rel. Joaquim Barbosa, Tribunal Pleno, DJe 22.05.2014), MS 33.984 AgR, Rela. Min. Dias Toffoli, Segunda Turma, DJe 28.04.2016, Rcl 20.043 AgR, Rel. Min. Dias Toffoli, Segunda Turma, DJe 26.06.2018, MS 37.703 AgR, Rel. Min. Dias Toffoli, Primeira Turma, DJe 15.06.2021.

Não parece que seja por motivo diverso que o STF tem rechaçado o cabimento de IRDR, ao dispor que "é da competência originária do tribunal estadual ou federal a que o juiz da causa estiver vinculado, pois em razão do regime de direito estrito, as hipóteses de ações, recursos e incidentes da competência da Suprema Corte estão taxativamente disciplinadas no art. 102 da Lei Maior".

É de sabença comum que no "dimensionamento da litigiosidade repetitiva", o CPC, em sintonia com as incidências para o exercício da competência, reservou ao STF o “incidente de resolução de recursos extraordinários repetitivos, que, conjugado com a repercussão geral, prevista no $\S 3 .^{\circ}$ do art. 102 da Carta da República, permite a Suprema Corte, a partir de criteriosa admissibilidade de representativos da controvérsia, a seleção de temas constitucionais de envergadura maior, para a formação de pautas de condutas de observância obrigatória pelas instituições do sistema de justiça"29.

\footnotetext{
${ }^{27}$ MENDES, Gilmar; BRANCO, Paulo Gustavo Gonet. Curso de direito constitucional. 7. Ed. São Paulo: Saraiva, 2012, p. 1.325 .

${ }^{28}$ CANOTILHO, José Joaquim Gomes. Direito constitucional e teoria da Constituição. 5. Ed. Coimbra: Almedina, 2002, p. 543.

${ }^{29}$ STF, Pet. n. ${ }^{\circ}$ 8.245. Min. Dias Toffoli, DJe 14.10.2019.
} 
Revista Eletrônica de Direito Processual - REDP.

Rio de Janeiro. Ano 16. Volume 23. Número 1. Janeiro a Abril de 2022

Periódico Quadrimestral da Pós-Graduação Stricto Sensu em Direito Processual da UERJ

Patrono: José Carlos Barbosa Moreira (in mem.). ISSN 1982-7636. pp. 678-694 www.redp.uerj.br

Logo, a Constituição Federal não delegou à lei e, aos Regimentos Internos são $\operatorname{vedados}^{30} 31$, estabelecer alteração ou fixação de novas competências originárias ao STF, não detendo, portanto, esse Tribunal atribuição para conhecer, processar e julgar IRDR.

A mesma intelecção deve ser transportada para o descabimento do IRDR perante o STJ; a uma porque sua competência originária e recursal decorre diretamente da Constituição Federal, não havendo nenhuma delegação à legislação ordinária para extensões ou supressões e, a dois, porque Regimentos, a partir de 1988, não inovam na ordem jurídica processual. Sua missão é disciplinar o funcionamento administrativo do Tribunal, a exemplo, da instauração, formações e composição de seus órgãos e a procedimentalística, em geral como desdobramentos relativos à concretização das competências constitucionais a eles reservadas pelo constituinte originário ou reformador.

Com efeito, tanto norma regimental no âmbito do STJ que discipline, para além da admissão, processamento e julgamento da suspensão nacional de processos em $\operatorname{IRDR}^{32} \mathrm{e}$ outras questões administrativas, quanto o funcionamento do julgamento dos recursos especiais eventualmente interpostos contra decisão oriunda de IRDR decidido pelos Tribunais de Justiça e Tribunais Regionais Federais ${ }^{33}$, são inconstitucionais.

\footnotetext{
${ }^{30}$ Em relação ao RISTF, destacamos: “O Regimento Interno aprovado em 15-10-80 tinha por objetivo regulamentar 'o processo e julgamento dos feitos` de sua competência (art. $1^{\circ}$ ). Ora, a CF de 1988 não permite que os Regimentos Internos dos Tribunais regulamentem questões processuais [art. 96]. (...) Devemos entender que a autorregulação de questões processuais é vedada também ao STF, pois a Constituição vigente não incluiu normas semelhantes ao art. 115 da CR de 1967. Diante disso, deveríamos concluir que não está mais vigorando o Regimento Interno de 1980, que autorregulamentava o processo e o julgamento no STF. O próprio STF analisou a constitucionalidade do Regimento que ele tinha criado e decidiu que a Constituição de 1988 recepcionou-o onde não há incompatibilidade de conteúdo. Segundo esse posicionamento, o STF não pode criar novas regras processuais, mas pode seguir as que já estabeleceu no Regimento Interno”. DIMOULIS, Dimitri; LUNARDI, Soraya. Curso de processo constitucional: controle de constitucionalidade e remédios constitucionais. 7. Ed. São Paulo: Thomson Reuters Brasil, 2020, p. 273-274.

${ }^{31}$ Como sustenta Carla Regina Clark da Costa, "não raro é declarada a inconstitucionalidade de artigos e incisos regimentais por disciplinarem questões de cunho eminentemente processual, que extrapolam os limites estabelecidos pela Constituição, invadindo reserva legislativa do Congresso Nacional”. COSTA, Carla Regina Clark da. Processo constitucional e normas procedimentais dos Regimentos Internos dos Tribunais. 2014. Dissertação (Mestrado em Direito) - Faculdade de Direito, Pontifícia Universidade Católica de Minas Gerais - PUC-MG -, 2014, p. 56.

${ }^{32}$ Vide: SIRDR - art. 21, XIII, alínea “m” e art. 67, parágrafo único, IV-A c.c. art. 271-A do RISTJ.

${ }^{33}$ Vide: art. 255 e art. 256-G/H do RISTJ.
} 
Por fim, em vista do fato de que o cabimento do IRDR perante os Tribunais Superiores, nomeadamente, o STM e o $\mathrm{TST}^{34}$, vem servindo de argumento favorável à admissibilidade do "incidente" perante o STJ, cabe tecer algumas considerações. Veja-se:

Em primeiro lugar, a Constituição Federal, em seu art. 124, estabeleceu que à “Justiça Militar compete processar e julgar os crimes militares definidos em lei”, delegando à legislação ordinária, a disposição quanto à organização, o funcionamento e a competência da Justiça Militar.

Diversamente do que estatuído para o STF e STJ, constituinte expressamente transferiu ao legislador comum a disciplina tanto da organização quanto a competência funcional do STM.

Nota-se, que no âmbito da justiça militar, a competência é estabelecida exclusivamente por lei. Aliás, a Lei n. ${ }^{\circ}$ 8.457/1992 compôs toda a estrutura organizacional dessa justiça especializada, inclusive, evidenciando que compete ao STM julgar os incidentes processuais previstos em lei (CPC e o CPPM, entre outros diplomas aplicáveis a essa justiça castrense), definindo em norma regimental a processualísticas inerente à admissão, conhecimento e julgamento do "incidente de resolução de demandas repetitivas" 35 (art. 157 usque 159 do RISTM).

O mesmo ocorre com a possibilidade de admissão do IRDR perante o TST. A Constituição Federal dispôs nos art. 111-A, § 1. ${ }^{\circ}$ c.c. art. 113 e 114, IX algumas competências do TST, outorgando à lei criar outras hipóteses de atuação do Tribunal. A Lei n. ${ }^{\circ}$ 7.701/1988, no que lhe concerne, atribuiu ao Regimento Interno do TST (Resolução administrativa n. ${ }^{\circ}$ 1.937/2017), disciplinar, nos termos da legislação processual vigente (CLT e CPC, por exemplo), uma série de incidentes procedimentais, entre eles o IRDR, “com relação às causas de sua competência originária e recursal ordinária”, conforme se pode constatar da compreensão dos arts. 305 usque 307 do RITST.

Pretender justificar o cabimento do IRDR perante o STJ a partir da análise de sua admissão em outros Tribunais Superiores, olvidando-se em analisar elementos imprescindíveis, data maxima venia, incorre em falácia (ad ignorantiam).

\footnotetext{
${ }^{34}$ SOARES, Fábio Costa. Cabimento do incidente de resolução de demandas repetitivas. In MENDES, Aluisio Gonçalves de Castro; PORTO, José Roberto Mello. Coords. Incidente de resolução de demanda repetitivas: panorama e perspectivas. Salvador: Juspodivm, 2020, p. 485-486.

${ }^{35}$ STM, Tribunal Pleno, Incidente de Resolução de Demandas Repetitivas n. ${ }^{\circ}$ 7000425-51.2019.7.00.0000, Min. Péricles Aurélio Lima de Queiroz, DJe 06/09/2019.
} 
Conclui-se, ao menos, diante do panorama constitucional e infraconstitucional vigente que não é cabível o IRDR, quer em relação às ações de competência funcional originária, quer, ainda, no que se refere às espécies recursais ordinária no âmbito do STF e do STJ.

\section{CONSIDERAÇÕES FINAIS}

O IRDR não se caracteriza como um genuíno incidente processual. É um instituto sui generis; uma criação brasileira.

A vocação do "incidente", primordialmente, está reservada aos Tribunais de Justiça dos Estados e aos Tribunais Regionais Federais, podendo sua admissão alcançar outros Tribunais Superiores, como o STM e TST, em vista do fato de a própria Constituição Federal franquear ao legislador comum fixar, total ou parcialmente, as competências funcionais desses órgãos do Poder Judiciário.

É incabível em relação às ações originárias e recursal-revisional ordinárias processadas perante o STF e o STJ. A esses Tribunais, a Constituição prescreveu competência funcional "numerus clausus", vedando a criação de espécies de demandas ou recursos fora daqueles estipulados nos art. 102, I e III, bem como art. 105, I e III da Constituição Federal.

A lei - o CPC - destinou ao STF e ao STJ, desdobramentos procedimentais acessórios, adequados e conectados aos permissivos constitucionais que disciplinam as hipóteses de cabimento dos recursos excepcionais, com o fito de enfrentar e solucionar conflitos repetitivos e de uniformização da jurisprudência, mantendo a higidez contemplada no Texto Maior. Não se criaram novas hipóteses de cabimento de recursos extraordinário e especial alijadas da Constituição Federal, tampouco "recursos extraordinários e especiais repetitivos" (CPC, art. 994). As espécies recursais são as mesmas, variando, com amparo na lei ordinária, a procedimentalidade quanto à forma de julgamento (CPC 1.036 usque 1.041). Concretiza-se a competência recursal posta na Constituição Federal (CF, art. 102, III e $\S 3 .^{\circ}$ e art. 105 , III).

Já em relação às ações de competência originária processadas e julgadas pelo STF e STJ, nenhuma alteração constitucional foi implementa para permitir o manejo do 
"incidente" visando à resolução de questões comuns repetitivas existentes no bojo de uma das espécies de ações previstas no rol de tipo cerrado do art. 102, I da Constituição Federal. A permissão contida o art. 978, parágrafo único, do CPC, não alcança aquelas ações originárias cuja previsão transcende a mera legalidade ordinária; exige-se, alteração no Texto Constitucional.

No episódio do julgamento da Pet. n. ${ }^{\circ}$ 11.838-MS - referendado por significativa parcela da doutrina -, o STJ pode ser considerado um Tribunal ativista, na medida em que, mesmo que aparentemente tenha se mantido em sua esfera de "competência", firmou um entendimento que não se baseia em uma interpretação plausível do Texto Constitucional ${ }^{36}$. In casu, foi-se além: interpretou-se o art. 105, I da Constituição à luz do CPC (art. 978, parágrafo único), caracterizando-se, assim, uma hermenêutica inconceptível.

Podemos até discordar, entender que não é justo ou coerente com a tão sanha de combate à "litigiosidade de massa" e internar mudanças, mas essas devem ser realizadas na arena política por meio do processo legislativo adequado. Jamais, por uma interpretação que não encontra lastro na Constituição Federal.

\section{REFERÊNCIAS:}

ABELHA, Marcelo. Suspensão da segurança: sustação da eficácia de decisão proferida contra o Poder Público. 2. ed. São Paulo: RT, 2006.

ALVIM, Arruda. Manual de direito processual civil. 19. Ed. São Paulo: Thomson Reuters Brasil, 2020.

ALVIM, Teresa Arruda et al. (Coords.). O CPC de 2015 visto pelo STJ [livro eletrônico]. São Paulo: Thomson Reuters Brasil, 2021.

ASSIS, Araken. Manual dos recursos [livro eletrônico]. 4. Ed. São Paulo: Thomson Reuters, 2021.

BUENO, Cassio Scarpinella. Manual de Direito Processual Civil. 2. Ed, São Paulo: Saraiva, 2016.

\footnotetext{
${ }^{36}$ SILVA. Virgílio Afonso da. Direito constitucional brasileiro. São Paulo: Editora Universidade de São Paulo, 2021, p. 509-510.
} 
CANOTILHO, José Joaquim Gomes. Direito constitucional e teoria da Constituição. 5. Ed. Coimbra: Almedina, 2002.

CAVALCANTI, Marcos de Araújo. Incidente de resolução de demandas repetitivas (IRDR) [livro eletrônico]. São Paulo: RT, 2016.

COSTA, Carla Regina Clark da. Processo constitucional e normas procedimentais dos Regimentos Internos dos Tribunais. 2014. Dissertação (Mestrado em Direito) Faculdade de Direito, Pontifícia Universidade Católica de Minas Gerais (PUC-MG), 2014

DIDIER JR, Fredie; CUNHA, Leonardo Carneiro da. Curso de direito processual civil. vol. 3. 17. Ed. Salvador: Juspodivm, 2020.

DIMOULIS, Dimitri; LUNARDI, Soraya. Curso de processo constitucional: controle de constitucionalidade e remédios constitucionais. 7. Ed. São Paulo: Thomson Reuters Brasil, 2020.

FERNANDES, Ricardo Yamin. Do incidente de assunção de competência [livro eletrônico]. São Paulo: Thomson Reuters Brasil, 2020.

LEMOS, Vinícius Silva. Recursos e processos nos tribunais. 5. Ed. Salvador: Juspodivm, 2021.

MARINONI, Luiz Guilherme; ARENHART, Sérgio Cruz; MITIDIERO, Daniel. Código de processo civil comentado [livro eletrônico] 4. Ed. São Paulo: Thomson Reuters Brasil, 2018.

MARINONI, Luiz Guilherme. Incidente de resolução de demandas repetitivas [livro eletrônico]: decisão de questão idêntica x precedente. 2. Ed. São Paulo: Thomson Reuters Brasil, 2019.

MEDINA, José Miguel Garcia. Curso de direito processual civil moderno [livro eletrônico]. 4. Ed. São Paulo: RT, 2018.

MENDES, Aluisio Gonçalves de Castro; TEMER, Sofia. O incidente de resolução de demandas repetitivas do novo código de processo civil. Revista de Processo REPRO. São Paulo, RT, vol. 243/2015. Maio/2015. Versão eletrônica.

Incidente de resolução de demandas repetitivas: sistematização, análise e interpretação do novo instituto processual. Rio de Janeiro: Forense, 2017. 
; PORTO, José Roberto Mello. Coords. Incidente de resolução de demanda repetitivas: panorama e perspectivas. Salvador: Juspodivm, 2020.

MENDES, Gilmar; BRANCO, Paulo Gustavo Gonet. Curso de direito constitucional. 7. Ed. São Paulo: Saraiva, 2012.

MONNERAT, Fábio Victor da Fonte. Súmulas e precedentes qualificados. São Paulo: Saraiva, 2019.

NEVES, Antônio Castanheira. Questão-de-facto e questão-de-direito. O problema metodológico da juridicidade (ensaio de uma reposição crítica). Coimbra: Almedina, 1967.

NEVES, Daniel Amorim Assumpção. Manual de direito processual civil. 12. Ed. Salvador: Juspodivm, 2020.

NERY JUNIOR, Nelson; NERY, Rosa Maria de Andrade. Código de processo civil comentado [livro eletrônico]. 5. Ed. São Paulo: Thomson Reuters Brasil, 2020.

NUNES, Dierle. O IRDR do Novo CPC: este "estranho" que merece ser compreendido. Revista Justificando: http://justificando.com/2015/02/18/o-irdr-novo-cpc-este-estranho-quemerece-ser-compreendido. Acesso: 08/10/2021

RIBEIRO, Sérgio Luiz Almeida. Incidente de Resolução de Demandas Repetitivas - IRDR: o procedimento padrão tupiniquim e suas peculiaridades; Revista Brasileira de Direito Processual - RBDPro, n. 92. Belo Horizonte, out/dez. 2015.

ROCHA, Alexandre. Julgamento de casos repetitivos e processo constitucional. Belo Horizonte: D'Plácido, 2018.

ROSSI, Júlio César. Crítica ao incidente de resolução de demandas repetitivas: das inadequações às inconstitucionalidades. Curitiba: Juruá, 2016. Versão digital.

SANTOS, Silas Silva et al (Coords). Comentários ao código de processo civil [livro eletrônico]: perspectivas da magistratura. 2. Ed. São Paulo: Thomson Reuters Brasil, 2020 .

SILVA. Virgílio Afonso da. Direito constitucional brasileiro. São Paulo: Editora Universidade de São Paulo, 2021.

SOARES, Fábio Costa. Cabimento do incidente de resolução de demandas repetitivas. In: MENDES, Aluisio Gonçalves de Castro; PORTO, José Roberto Mello. Coords. 
Incidente de resolução de demanda repetitivas: panorama e perspectivas. Salvador: Juspodivm, 2020.

THÉRY, Philippe. Competência. In: ALLAND, Denis; RIALS, Stéphane (Orgs.). Dicionário de Cultura jurídica. São Paulo: WMF Martins Fontes, 2012.

VOLPE CAMARGO, Luiz Henrique. A centralização de processo como etapa necessária do incidente de resolução de demandas repetitivas. 2017. Tese (Doutorado em Direito) - Faculdade de Direito, Pontifícia Universidade Católica de São Paulo (PUC-SP), 2017.

WAMBIER, Luiz Rodrigues; TALAMINI, Eduardo. Curso avançado de processo civil: cognição jurisdicional (processo comum de conhecimento e tutela provisória) - vol. 2, 16. ed. São Paulo: RT, 2016. 